\title{
EFEITOS DO APAGAMENTO DA EXCEÇÃO NA CONTEMPORANEIDADE ${ }^{1}$
}

EFFECTS OF THE ERASING OF EXCEPTION IN CONTEMPORANEITY

EFECTOS DE LA SUPRESIÓN DE LA EXCEPCIÓN EN LA ÉPOCA CONTEMPORÁNEA

\author{
Michelle Santos Sena de Oliveira* \\ Antônio Márcio Ribeiro Teixeira*
}

\begin{abstract}
RESUMO
No contexto de uma predominância de práticas avaliativas e de vigilância que incidem nos diversos domínios da vida contemporânea, este artigo tem como objetivo elucidar os efeitos do apagamento da exceção na Contemporaneidade sob o viés psicanalítico. Do discurso do mestre antigo ao discurso do mestre moderno, universitário e capitalista, o saber obtido pelo cálculo da utilidade e do valor passa a orientar as decisões políticas e individuais. Diante dessa realidade, a administração burocrática se direciona aos sujeitos, visando a homogeneizá-los e submetê-los ao ideal de transparência moderno, garantido pelo saber extraído e decodificado pelos instrumentos de avaliação. A psicanálise recolhe os efeitos desse laço social contemporâneo, mas, de forma distinta do discurso dominante, oferece outro destino ao íntimo, ao que do gozo não pode ser contabilizado e homogeneizado.
\end{abstract}

Palavras-chave: Psicanálise. Modernidade. Capitalismo. Discurso. Gozo.

\begin{abstract}
In the context of a predominance of evaluative and surveillance practices which fall upon various domains of contemporary life, this article aims to elucidate the erasing of exception paths and effects on contemporaneity from a psychoanalytic standpoint. From the ancient master's discourse to the modern master's discourse, academic and capitalist, the knowledge obtained by utility and value measures starts to direct political and individual decisions, previously guided by tradition. In the face of this reality, the bureaucratic administration gear towards the subjects, striving for homogenizing and
\end{abstract}

Texto recebido em 25 de abril de 2017 e aprovado para publicação em 16 de março de 2018.

1 Este artigo é fruto da dissertação mestrado intitulada Efeitos do apagamento da exceção na Contemporaneidade, de Michelle Santos Sena de Oliveira (2017), orientada pelo Prof. Antônio Márcio Ribeiro Teixeira, apresentada ao Programa de Pós-Graduação em Psicologia da Universidade Federal de Minas Gerais (UFMG).

* Mestra em Psicologia (Estudos Psicanalíticos) pela UFMG, pós-graduada em Clínica do Acompanhamento Terapêutico pela Pontifícia Universidade Católica de Minas Gerais (PUC Minas), graduada em Psicologia pela Universidade Fumec. E-mail: michellessena@gmail.com.

** Doutor em Psicanálise (Paris VIII), mestre em Filosofia Contemporânea, professor associado da Faculdade de Filosofia e Ciências Humanas da UFMG, médico, psiquiatra. E-mail: amrteixeira@uol.com.br. 
subordinating them to the modern ideal of transparency, guaranteed by the knowledge extracted and decoded by the evaluation apparatus. Psychoanalysis garners the effects from this contemporary social bond, but, in a distinct way from that of the dominant discourse, offers another destiny to the intimate, to the jouissance that can be neither accounted for, nor homogenized.

Keywords: Psychoanalysis. Modernity. Capitalism. Discourse. Jouissance.

\section{RESUMEN}

En el contexto de un predominio de prácticas evaluativas y de vigilancia que inciden en los diversos dominios de la vida contemporánea, este artículo tiene como objetivo elucidar los efectos de la supresión de la excepción en la contemporaneidad bajo el enfoque psicoanalítico. Del discurso del viejo maestro al discurso del maestro moderno, universitario y capitalista, el conocimiento adquirido por el cálculo de la utilidad y del valor empieza a guiar las decisiones políticas e individuales. Ante esta realidad, la administración burocrática se dirige a los sujetos con el fin de homogeneizarlos y someterlos al ideal de la transparencia moderno, garantizado por el conocimiento extraído y decodificado por los instrumentos de evaluación. El psicoanálisis recoge los efectos de ese lazo social contemporáneo, pero, de forma distinta del discurso dominante, ofrece otro destino al íntimo, en el que el goce no puede ser contabilizado y homogeneizado.

Palabras clave: Psicoanálisis. Modernidad. Capitalismo. Discurso. Goce.

\section{EFEITOS DO APAGAMENTO DA EXCEÇÃO NA CONTEMPORANEIDADE}
1 ciência e a tecnologia invadiram a vida cotidiana por meio de instrumentos que guiam as tomadas de decisões em diferentes contextos. $\mathrm{Na}$ Contemporaneidade, o saber proveniente dos gadgets (dispositivos eletrônicos e aplicativos que contabilizam e interpretam dados, assim como o que resulta dos questionários de avaliação) é utilizado a fim de orientar diversas atividades. A vigilância e o monitoramento por câmeras coletam dados e imagens que orientam políticas de segurança para espaços públicos e privados. No contexto social, percebemos que dados extraídos de instrumentos estatísticos conduzem decisóes e políticas nos mais diversos setores do governo. Tudo e todos estão sendo incessantemente observados e avaliados. O "olho absoluto", que coloca todos os indivíduos sob supervisão, fundamenta-se no ideal cientificista de transparência e na política preventiva e securitária (Wajcman, 2011). 
Para abordar as mudanças no laço social provenientes do avanço do discurso científico e do desenvolvimento dos gadgets, orientamo-nos por algumas indicações lacanianas.

Em 1967, Lacan (1967a/2003) ${ }^{2}$ anunciava uma mudança na civilização: a entrada em uma era "planetária" (p. 360), efeito do progresso da ciência nas estruturas sociais. Considerando a função civilizatória de controlar o gozo, ideia já desenvolvida por Freud, o autor salienta que a filosofia e a religião não seriam mais os revestimentos dessa função, e que ela passaria a se apresentar de forma "nua" (Lacan, 1967a, p. 362). Assim, podemos inferir que o controle das pulsões, antes promovido pela religião e pelas leis fundadas no significante-mestre, foi substituído pelo saber científico e pelo valor do mercado capitalista.

Lacan (1959-1960/2008) também aponta um "declínio radical da função do mestre" (p. 23) que ocorre na Modernidade e que está relacionado ao aparecimento da teoria utilitarista. Mais adiante, no Seminário 17, Lacan (1969-1970/1992) indica que o discurso do mestre antigo é modificado pelo desenvolvimento da ciência e do capitalismo e, a partir da estrutura do discurso universitário, apresenta uma nova forma de revestimento, a tentativa moderna de controlar o gozo: o imperativo de "tudo saber" (Lacan, 1969-1970, p. 32).

Situamos como nossa hipótese a substituição do discurso do mestre antigo por um discurso do mestre moderno que comporta o saber científico e utilitário em sua posição de agente, promovendo a supressão da exceção. Em contraposição à função de exceção fundadora do discurso do mestre, a administração do cientista utilitário parece se exercer mediante o saber extraído da classificação e avaliação dos indivíduos.

\section{O APAGAMENTO DA EXCEÇÃO NA MODERNIDADE}

A Modernidade é caracterizada pela secularização do mundo e pelo distanciamento do saber tradicional, suportado por uma exceção, que organizava a estrutura social de forma hierárquica. O questionamento do saber antigo ocorre com base em fundamentos racionais decorrentes do novo pensamento científico e filosófico. De acordo com Mackenzie (2011), a modificação na ordem política, econômica e social do mundo ocorre pela transformação da orientação presente desde a Antiguidade, na qual a ordem política era determinada hierarquicamente e com base em fundamentos religiosos. Segundo o autor, podemos simplificar a história da Era Moderna a partir de três núcleos: o nascimento do capitalismo, o surgimento da ciência moderna e a modificação na forma de reflexão filosófica.

2 A primeira data indica o ano de publicação da obra, e a segunda, a edição consultada pelo autor, a qual somente será pontuada na primeira citação da obra no texto. Nas seguintes, será registrada apenas a data de publicação original. 
$\mathrm{Na}$ Modernidade, "as pessoas começaram a rebelar-se e a derrubar as ordens estabelecidas que promovessem e sustentassem aquelas formas de ordem política" (Mackenzie, 2011, p. 30). É importante ressaltar que, após o questionamento da ordem antiga, discutiu-se quais formas de condução seriam possíveis para que uma anarquia fosse evitada.

Historicamente, a Revolução Francesa marca o questionamento dos princípios que sustentavam o poder na garantia divina, ao propor a igualdade dos cidadãos perante a lei, o que, desde então, define o fundamento do direito (Miller, 2005a). Assim, Miller (2005a) sustenta que a supressão da exceção pode ser considerada a maior conquista desse movimento. Vale ressaltar que nossa investigação a respeito da substituição da exceção pela equidade, no contexto social revolucionário apontado acima, encontra correspondência no pensamento de Rousseau.

O contrato social (Rousseau, 1762/2014) propõe a regulação da ordem social, situando a vontade geral do povo como o próprio poder soberano. Para que esse contrato fosse possível, toda a divisão administrativa do poder e dos representantes do povo soberano seria articulada à necessidade da criação de mecanismos de controle que assegurassem a equivalência entre todos os indivíduos e a prevalência da vontade soberana do povo em detrimento dos interesses pessoais. O pensamento de Rousseau, como princípio que sustenta os ideais da Revolução Francesa, marca o discurso teórico político da Modernidade a partir de seu "axioma da igualdade primordial entre as pessoas" (Lizárraga, 2015, p. 51, tradução nossa).

$\mathrm{Na}$ Modernidade, simultaneamente ao apagamento da exceção, ocorre a modificação na forma de pensamento e a orientação por um saber derivado da racionalidade. $\mathrm{O}$ modelo da ciência moderna, o saber racional, passa, de certa forma, a guiar a ordenação social do mundo, produzindo efeitos na política e nos sujeitos. Interessa-nos remeter ao cientificismo como conceito que esclarece que a racionalidade, o método científico moderno, transborda a própria ciência. O cientificismo é "a ideia de que o espírito e os métodos da ciência deveriam ser estendidos a todos os domínios intelectuais e morais da vida, sem exceçôes" (Lalande, 1926/1988, p. 960, tradução nossa).

É importante realçar, a partir da análise de Sartre (1994), que essa nova forma de organização social instaura o princípio da igualdade entre os homens, em contraposição à diferença antes estabelecida entre os governantes e governados, o que serve para que o homem burguês desqualifique a nobreza e possa ter uma posição social que não necessite da validação da tradição. O princípio igualitário é nomeado como "humanismo burguês" (Sartre, 1994, p. 21, grifo do autor) e 
propõe uma falsa universalidade que se utiliza das leis científicas baseadas na razão para constituir sua ideologia que visa ao lucro e à utilidade.

A instalação do capitalismo propõe a reificação, a objetificação dos homens e das coisas. O princípio capitalista de equivalência geral desconsidera o valor de uso, sempre qualitativo, em favor do valor de troca, sempre calculável (Lukács, 2003). Esse princípio de equivalência geral passa a ser empregado pela organização política, moderna e contratual, para garantir, via cálculo, a equivalência entre os homens.

Quanto ao desenvolvimento das formas modernas de governo, seguimos a observação de Lacan (1959-1960) sobre a ocorrência "de um declínio radical da função do mestre" (p. 23), na mesma época da instalação da teoria utilitarista por Bentham. ${ }^{3}$

Corroborando a conexão entre o utilitarismo e esse momento histórico pósrevolucionário, Sartre (1994) localiza que a ideologia dominante da burguesia propõe a construção do pensamento científico baseado na racionalidade, instalando a utilidade como sua meta, visando à técnica e à prática. A relação entre o utilitarismo e a racionalidade moderna é realçada por Bobbio (1995). Bentham, também chamado "Newton da legislação" (Bobbio, 1995, p. 91), desenvolve a teoria utilitarista com a finalidade de criar uma ética objetiva baseada na racionalidade, fundamentando-se em um "princípio objetivamente estabelecido e cientificamente verificado, do qual se pode deduzir todas as regras para o comportamento humano, que passam assim a ter o mesmo valor das leis descobertas pelas ciências matemáticas e naturais" (Bobbio, 1995, p. 92).

Foucault (2015) retoma o pensamento de Rousseau e o conecta à teoria utilitarista. Para o autor, o sonho dos revolucionários, a transparência total do contrato, complementa-se com o poder onividente, um poder saber sobre tudo, materializado no pan-óptico de Bentham, modelo no qual a teoria utilitarista se apresenta de forma mais pura. ${ }^{4}$ Então salienta que o sonho dos revolucionários é o "de uma sociedade transparente, ao mesmo tempo visível e legível em cada uma de suas partes; que não haja mais nela zonas obscuras, zonas reguladas pelos privilégios do poder real" (Foucault, 2015, p. 326).

Com o apagamento da exceção na Modernidade, o utilitarismo fornece um novo modelo de organização social, uma tentativa de racionalizar o Estado e de

3 Bentham (1748-1832), considerado o pai da teoria utilitarista, tinha formação em Direito e se dedicou ao estudo da Ciência do Direito e suas relaçóes com a Economia e a Filosofia. Participou de um grupo de pensadores ingleses, chamado radicais filosóficos, que se interessava pelas reformas políticas e sociais na Inglaterra.

$4 \mathrm{O}$ pan-óptico foi concebido por Bentham, no século XVIII, como um dispositivo de vigilância como modelo de arquitetura para as prisões, sendo também ampliado para outras instituiçóes escolares, assistenciais e de trabalho. A vigilância a partir de uma torre central permitiria que um vigilante pudesse observar a todos os encarcerados (presos, trabalhadores, estudantes ou pacientes) sem que estes pudessem saber se estavam ou não sendo vistos. O modelo considerava o máximo de utilidade para as questôes econômicas, de segurança e preventivas (Bentham, 1787/2008). 
manter o axioma da igualdade entre os indivíduos, propondo a administração de qualquer instituição por meio de uma objetificação e classificação minuciosas, aqui relacionadas ao ideal de transparência, fundamental para que o regime moderno, que não suporta a exceção, possa subsistir. $\mathrm{O}$ cálculo e a utilidade garantem a legitimidade dessa administração fundamentada no saber racional que propõe o útil como a "única instância de legitimação" (Miller, 2008, p. 117), pois "foraclui toda garantia natural ou divina” (Miller, 2008, p. 117).

Bentham (1776/1988) salienta o axioma fundamental da teoria utilitarista: " $o$ máximo de felicidade do maior número de pessoas é a medida do certo e do errado" (p. 3, grifo do autor, tradução nossa), o que pode ser entendido como o cálculo da felicidade como uma medida que serve a todos e qualquer um. Assim, "nesse nível de homogeneidade, a lei da utilidade, como que implicando sua repartição pela maioria, se impõe por si mesma como uma forma que, efetivamente, inova" (Lacan, 1959-1960, p. 234).

Em contraposição à antiga ideologia do prazer, "a felicidade tornou-se um fator de política” (Lacan, 1959-1960, p. 342) na Modernidade. A questão do bem "deixou de ser uma questão abstrata para se tornar objeto de um cálculo político" (Teixeira, 1999, p. 167). As produções dos homens, sua relação com a satisfação de suas necessidades e com o desejo marcam a "encruzilhada do utilitarismo" (Lacan, 1959-1960, p. 273). As necessidades dos homens passam a ser regidas pela máxima da utilidade. O utilitarismo realiza "uma abordagem da questão do bem e do valor de uso inteiramente inserida no nível do significante" (Teixeira, 1999, p. 171).

Bentham "é o homem que aborda a questão no nível do significante" (Lacan, 1959-1960, p. 273). O utilitarismo, ao situar o bem na esfera da utilidade e oferecer a felicidade ao maior número de pessoas, opera no nível do axioma de igualdade proposto pela orientação política pós-revolucionária. Essa questão é realçada por Lacan (1959-1960) ao dizer que o utilitarismo se relaciona com "o poderio uniformizador de uma certa lei de igualdade, a que se formula na noção de vontade geral" (p. 234). De acordo com Teixeira (1999), "o utilitarismo pode ser visto como o discurso que soube finalmente instituir, no lugar ausente do Pai, um princípio de organização coletiva fundado sobre a equivalência imaginária do outro" (p. 175). 


\section{DO MESTRE ANTIGO AO MESTRE MODERNO}

Para adentrar o campo dos discursos, Lacan (1968-1969/2008) aborda o objeto $a$ na forma do mais de gozar, exemplificando como o gozo é incluso no discurso, no campo do Outro. Evidenciando a ruptura causada pela ciência, juntamente com o capitalismo, o psicanalista indica como o manejo do gozo, pela via do significante calculável, opera no tratamento da inconsistência do Outro. Para elaborar os discursos, ele realiza um tratamento lógico da inconsistência do Outro, fomentando novas ordenações discursivas que não são comandadas pela exceção, pelo significante-mestre.

A ordenação discursiva é abordada por Lacan (1968-1969/2008) na forma de "uma ordem simbólica" (p. 286), pois ele não considera que exista "a" ordem simbólica, uma única ordem, e sim diversas ordenações possíveis. Nessa sequência, diz: "O que é uma ordem simbólica? É mais do que apenas uma lei, é também uma acumulação, ainda por cima numerada. É uma ordenação" (Lacan, 1968-1969/2008, p. 286). Nesse sentido, o psicanalista salienta que a contagem é fundamental na organização social, pois "aquele que sabe contar pode repartir; ele distribui e, por definição, quem distribui é justo. Todos os impérios são justos" (Lacan, 1968-1969/2008, p. 288). O que fica destacada é a maneira como o significante faz parte dos mecanismos de poder.

A racionalidade moderna apresenta sua tentativa de tratar a inconsistência do Outro reduzindo o mundo ao contável. Nesse sentido, Lacan (1968-1969/2008) relaciona a ordem simbólica moderna com os empórios, "lojas em que tudo é bem organizado" (p. 287), e observa que sua diretriz provém dos significantes extraídos do cálculo. Em suas elaborações, o psicanalista expõe como o discurso moderno sugere coordenar os modos de gozo, oferecendo um suplemento de gozo, o mais de gozar, por meio da orientação pelo valor definido no mercado capitalista. Como não há um Outro consistente, uma exceção que assegure a ordenação social, a ciência e o mercado assumem a gestão dos valores que vão regular e distribuir o gozo na sociedade.

A realidade se estrutura como um discurso a partir de um ordenamento simbólico (Lacan, 1969-1970/1992). Em sua conferência $D u$ discours psychanalytique, Lacan (1972) sustenta que a linguagem, essa marca que diferencia os homens dos animais, é o que possibilita a emergência de um mestre. Para que esse discurso do mestre funcione, basta que a linguagem exista, pois ela, por sua estrutura, introduz no mundo o significante-mestre $\left(S_{1}\right)$, que faz aparecer um saber $\left(\mathrm{S}_{2}\right)$ que lhe obedeça. $\mathrm{O}$ psicanalista sublinha que não é por acaso que iniciará a abordagem dos quatro discursos pelo discurso do mestre, e sim por 
razóes históricas, pois esse discurso constitui o ponto de partida para os outros três.

Figura 1 - Discurso do mestre

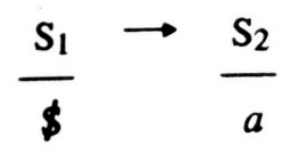

Fonte: Lacan (1969-1970/1992, p. 12.)

O significante-mestre, $S_{1}$, pode ser relacionado com o que Lacan (1960/1998) propõe ao introduzir o significante do Outro barrado como representante de uma falta estrutural no Outro da linguagem. Ao estabelecer que essa falta é necessária para o funcionamento da ordem simbólica, o autor ressalta que é nesse ponto que o pai morto do mito freudiano deve ser localizado (Lacan, 1969-1970/1992). Somente por sua falta é que o ordenamento significante pode ocorrer e o sujeito pode ser representado, sendo necessária a existência dessa função de exceção.

Verificamos a necessidade do pai morto, como exceção, para que a lei funcione e os irmãos sejam inclusos em uma sociedade regulada por leis. Teixeira (2015) ressalta que, "para que se possa instituir um conjunto de regras que se aplique a todos os membros de uma comunidade, é necessário que desse Universal se separe um elemento que a ele não se submete" (p. 1). Assim, o autor reitera que é necessário um gesto de exclusão, de negação, para que se funde o conjunto do universal.

O lugar do agente no discurso do mestre, o $S_{1}$, está marcado por essa condição de exceção. Lacan (1969-1970/1992) atribui especial valor ao lugar dominante nesse discurso, ocupado pelo $S_{1}$, pois é o único lugar onde a lei pode ser situada. Segundo o psicanalista, "se o discurso do mestre constitui o lastro, a estrutura, o ponto forte em torno do qual se ordenam diversas civilizaçóes, é porque seu motor, afinal, é de uma ordem muito diferente da violência” (Lacan, 1971/2009, p. 25).

Miller (2005b) relaciona a estrutura do discurso do mestre com o discurso da Antiguidade. Naquele período, o lugar da exceção era estruturante da organização social e a influência da racionalidade, da ciência moderna e do capitalismo, provocou uma modificação que instaurou um regime igualitário que não admitia a exceção. Essa mudança na forma de organização social pode ser relacionada ao que Lacan (1969-1970/1992) sugere como "uma modificação no lugar do saber" (p. 32), pois o significante-mestre que ocupava o lugar de agente no discurso do mestre é substituído pelo saber no discurso universitário. 
O desenvolvimento da ciência levou o cientista a não mais se referenciar na exceção e a "se contentar em aplicar mecanicamente as regras formais que o determinismo da ciência matematizada autoriza, sem se perguntar pela legitimidade de seu procedimento" (Teixeira, 2012, p. 220). Assim, a autoridade, a tradição e a religião não mais sustentam o saber e o poder; estes se tornam independentes da figura estruturante de exceção do mestre.

Com os avanços da ciência, a teoria do direito e da política também se modificam e passam a se referenciar por esse novo modelo, no qual o saber demonstrável ocupa o antigo lugar da exceção. Ocorre, então, o apagamento do fundamento de exceção que garantia o lugar do mestre. O que Lacan (1973/2003) introduz é que a ciência traz a ruína do mestre, pois, se o cientista "não seduzir o mestre, ocultando-lhe que nisso está sua ruína, esse saber permanecerá enterrado como esteve durante vinte séculos" (p. 312).

Lacan (1970/2003) ressalta que a ciência posiciona o sujeito no lugar de agente do discurso. É o discurso científico moderno que propicia aos sujeitos o questionamento do mestre da tradição e, a partir desses questionamentos, o que se produz é um novo saber, $S_{2}$. $\mathrm{O}$ recurso à matemática possibilitou a emergência desse discurso que rechaça a exceção, a sua verdade, e a produção de um novo tratamento simbólico do conhecimento. Sobre a ciência, Lacan (19691970/1992) indica o que

esse discurso tem de natureza afim à da matemática, onde A representa a si mesmo, sem precisar do discurso mítico para dar-lhe suas relações. É por aí que a matemática representa o saber do mestre como constituído com base em outras leis que não as do saber mítico. Em suma, o saber do mestre se produz como um saber inteiramente autônomo do saber mítico, e isto é o que se chama de ciência (p. 94).

A invenção de um novo discurso, não referenciado à tradição, é o pontochave do desenvolvimento científico. Localizando esse deslocamento de discurso, Lacan (1969-1970/1991) verifica que "um verdadeiro mestre, vimos isso em geral até uma época recente, e se vê cada vez menos, um verdadeiro mestre não deseja saber absolutamente nada - ele deseja que as coisas andem” (pp. 23-24, tradução nossa). Assim, o que ocorre é uma "modificação no lugar de saber" (Lacan, 1969-1970/1992, p. 32) e a instauração de um "discurso do mestre pervertido" (p. 194), do mestre interessado em saber.

Tais proposições nos permitem verificar que, na Modernidade, ocorre a instalação do discurso da ciência no lugar do discurso do mestre, e que esse mestre moderno afirma-se pela produção de um novo saber disjunto da tradição. O que ocorre no desenvolvimento histórico resulta no giro de discurso que posiciona o saber, $S_{2}$, como o agente do discurso. Para Lacan, esse mestre moderno 
Não tem a estrutura do antigo, no sentido de que este último se instala no lugar indicado sob esse $\mathrm{M}$ [discurso do mestre]. Ele se instala no da esquerda, encabeçado pelo $U$ [discurso universitário]. Eu lhes direi por quê. O que ocupa ali o lugar que provisoriamente chamaremos de dominante é isto, $S_{2}$, que se especifica por ser, não saber de tudo, nós não chegamos aí, mas tudo saber (Lacan, 1969-1970/1992, p. 32).

Segundo Brousse (2015), o que marca esse deslocamento de discurso é a apresentação do fim do reino do significante-mestre, o $S_{1}$. Assim, o império do Um, sustentado pela exceção, é substituído pelo Um contável do discurso matemático.

Figura 2 - Discurso universitário

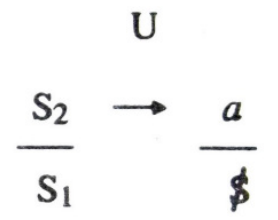

Fonte: Lacan, 1969-1970/1992, p. 29.

A diferença fundamental que se instala na mutação do discurso do mestre antigo ao discurso do mestre modernizado é que o saber, $\mathrm{S}_{2}$, ao ser colocado no lugar de agente, "não é o mesmo saber" (Lacan, 1969-1970/1992, p. 36). Esse giro discursivo que coloca o novo saber no posto de comando ocorre pela "introdução do mundo novo no horizonte, das puras verdades numéricas do que é contável" (Lacan, 1969-1970/1992, p. 84). Esse novo saber da ciência, $S_{2}$, é "um saber onde a necessidade é formal e que se articula pela necessidade da escritura" (Brousse, 1999, p. 168, tradução nossa). A ciência moderna modifica o manejo do saber de forma a excluir sua relação com a verdade como causa de desejo. Nesse giro discursivo, o tratamento do significante-mestre passa a ser realizado para escondê-lo, concedendo-o a posição de verdade do discurso. No lugar da verdade, o $S_{1}$ ordena: "Vai, continua. Não para. Continua a saber sempre mais" (Lacan, 1969-1970/1992, p. 110, grifo do autor).

Lacan (1969-1970/1992) ressalta os efeitos dessa "nova tirania do saber" (p. 32). O psicanalista frisa que, "pelo fato de o signo do mestre ocupar esse lugar, toda pergunta sobre a verdade é, falando propriamente, esmagada, silenciada" (Lacan, 1969-1970/1992, p. 110). Rechaçando o discurso mítico, a verdade é tratada formalmente. O saber, nesse discurso, torna-se impessoal e anônimo, ele está disjunto da qualidade, baseando-se somente no que pode ser deduzido quantitativamente. 
Ao refletir sobre a estrutura do discurso universitário, verificamos que o $\mathrm{S}_{2}$ não permite que a exceção apareça. O que não impede, como Lacan (1969$1970 / 1992)$ indica, que a verdade $\left(S_{1}\right)$ possa retornar de forma totalmente diversa de sua função estruturante no discurso do mestre. Lacan (1969-1970/1992) aponta o quanto o retorno da verdade no discurso modernizado pode ser catastrófico. De acordo com o psicanalista, "Todo discurso se apresenta prenhe de consequências, só que obscuras" (Lacan, 1968-1969/2008, p. 33) e novas consequências se apresentam a partir do discurso universitário. Diante disso, ele observa que "essa elevação do mestre ao saber foi que permitiu a realização dos mestres mais absolutos que jamais se havia conhecido desde os primórdios da história” (Lacan, 1968-1969/2006, p. 396, tradução nossa).

A burocracia seria a forma dessa gestão administrativa que tenta suprimir a exceção no modelo do discurso universitário, no qual o saber esconde o $S_{1}$, que ocupa o lugar da verdade inacessível ao sujeito. Nesse ponto, Miller (2005a) adverte que, "quando a norma se torna totalitária se paga com um retorno do mestre" (p. 214). Esse retorno catastrófico do mestre é apresentado por Miller (2005a) no exemplo da suspensão da Constituição da República de Weimar, realizada por Hitler.

Essa primeira mutação do mestre, efeito da ciência moderna, instala o saber na posição de agente do discurso e produz, a partir da manipulação do novo saber, as condiçôes para o estilo capitalista. A objetificação do mundo reduz todos os elementos e indivíduos ao seu aspecto quantitativo, incluindo o próprio saber. Ocorre a redução "dos saberes a um único mercado" (Lacan, 1968-1969/2008, p. 40). Essa mutação do mestre para seu estilo capitalista é referida ao momento histórico em que, "a partir de certo dia, o mais de gozar se conta, se contabiliza, se totaliza. Aí começa o que se chama de acumulação de capital" (Lacan, 19691970/1992, p. 189).

Nesse sentido, podemos entender que o novo saber, disjunto de uma garantia externa a ele, proporciona uma nova forma de extrair o mais de gozar, a maisvalia. O saber, "sob sua forma científica" (Lacan, 1968-1969/2008, p. 39), influencia a transformação do homem, do trabalhador, em mercadoria.

Lacan (1972) propõe uma escrita para o discurso do mestre capitalista, um discurso astucioso que substitui o antigo discurso do mestre. Na produção desse novo discurso, o psicanalista, também astucioso, vale-se de um artifício, da inversão do sujeito barrado e do $S_{1}$ na estrutura original do discurso do mestre. 


\section{Figura 3 - Discurso capitalista}

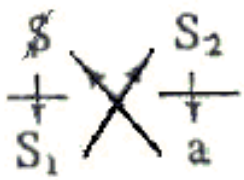

Fonte: Lacan, 1972.

Nesse discurso moderno, o tratamento do gozo pela via do valor tenta impor outro funcionamento do social ao suprimir a exceção. Ao mesmo tempo, o sujeito pode acessar o mais de gozar em sua forma de mercadoria, porém orientado no nível da necessidade, deslocado de sua relação com o desejo.

Entendemos que o mestre moderno capitalista, a "mão invisível" do mercado, fundamenta-se no tratamento formal da verdade pela racionalidade científica. Nessa direção, Lacan (1972) ressalta que o caminho da ciência é o de produzir um discurso a partir de ordenaçôes significantes cada vez mais puras, fórmulas cada vez mais distanciadas de um significado, referência que também podemos estender ao capitalismo. A partir desse saber puro, baseado em fórmulas lógicas e matemáticas, a ciência e o capitalismo criam novos objetos, os "gadgets" (Lacan, 1969-1970/1992, p. 157, grifo do autor). Laurent (1992) considera que o sentido dos objetos produzidos não importa à ciência, o que lhe importa é que se produza. A subtração realizada pela ciência, subtração de gozo, é devolvida nos objetos. O discurso do mestre moderno propõe coletivizar os homens a partir do saber e dos objetos que orientam o gozo, já que não dispõe da exceção para fundar o conjunto do "todos iguais".

O discurso universitário e o discurso capitalista rechaçam o que está no lugar da verdade, o $S_{1}$, promovendo uma gestão administrativa pelo saber e pelo valor. Lacan (1971-1972/2011) indica que há uma espécie de distração provocada por esses discursos, ao ressaltar que são discursos bem feitos, nos quais os sujeitos são "engambelados" (p. 61) e "sequer pensam nisso" (p. 61). De acordo com o psicanalista, "o capitalismo reina porque está estreitamente ligado à ascensão da ciência" (Lacan, 1968-1969/2008, p. 233), e o poder instaurado é "camuflado, esse poder secreto e, também cabe dizer, anárquico" (Lacan, 1968-1969/2008, p. 233). Podemos entender o que é introduzido como poder anárquico no sentido de que "torna-se muito mais difícil, segundo Lacan, localizar e nomear efetivamente o mestre ou senhor moderno" (Laia, 2009, p. 10). A verdade rechaçada nesse discurso modernizado propõe uma administração igualitária, sem mestre. 
Além disso, é importante ressaltar os efeitos segregativos e violentos do retorno da exceção, quando esta é apagada e posta no lugar de verdade rechaçada pelo discurso. A este efeito de retorno, podemos relacionar uma observação de Lacan (1967b) ao se referir aos campos de concentração "como consequência do remanejamento dos grupos sociais pela ciência, e, nominalmente, da universalização que ela ali introduz" (p. 263) e, com base nisso, o psicanalista sugere que "nosso futuro de mercados comuns encontrará seu equilíbrio numa ampliação cada vez mais dura dos processos de segregação" (p. 263).

\section{AVALIAÇÃO E VIGILÂNCIA: INSTRUMENTOS DO MESTRE MODERNO}

As modificações iniciadas na Modernidade tomam outros formatos com a expansão da globalização e, nesse mercado do saber, ocorre a "homogeneização dos saberes" (Lacan, 1968-1969/2008, p. 40) em torno de um valor quantitativo em prol de uma destituição das qualidades dos saberes, dos objetos e dos próprios sujeitos. De acordo com Miller e Milner (2006), a forma atual de administração do Estado, a democracia moderna, ao propor uma equivalência entre os sujeitos, torna-se o "lugar geométrico do contrato. Ou melhor, dos contratos, já que a força da norma contratual está em poder ser multiplicada de maneira ilimitada" (Miller, \& Milner, 2006, p. 6). O reino da lei e do Nome do Pai, representado pelo discurso do mestre, ordenava simbolicamente o mundo a partir de uma exceção. Com a Modernidade e a pluralização dos Nomes do Pai, esse discurso é substituído pelo discurso universitário, que fundamenta uma ordenação social igualitária, não permitindo a existência de uma exceção. A partir do momento em que a exceção é apagada, perde-se o limite, e a referência passa a ser o saber expresso no contrato.

Segundo Miller (2005), o modelo moderno é a pura administração comandada pelo saber, que se esforça para apagar a exceção. Milner (2002) sustenta que a democracia moderna também pulveriza a exceção ao multiplicar os poderes e as regras que passam a ser distribuídos entre diversas partes da sociedade. A exceção transformada em regra é enfraquecida e não sustenta a função de limite exterior, como fazia no antigo regime, não é mais o suporte para a resolução dos conflitos entre regras contraditórias (Milner, 2002).

A gestão administrativa moderna é fundamentada na lógica contratual e na igualdade entre os homens, exigindo a avaliação como atividade indispensável. O estabelecimento do moderno regime democrático do "todos iguais" não permite que a exceção tenha lugar. São necessárias a avaliação e a vigilância constantes, estratégias que preservam o ideal de transparência e permitem a homogeneização 
dos sujeitos. Torna-se difícil localizar o mestre no mundo moderno. No lugar do mestre estão a mão invisível do mercado e as novas comissões de especialistas. O lugar de comando do discurso do mestre moderno está ocupado pelo saber, científico e utilitário, que incide sobre todos, sem exceção. No mundo moderno, as exceções são inclusas e passam a serem prescritas pelo discurso normativo. Esse discurso pretende mascarar a heterogeneidade e propõe: para cada exceção, uma nova norma.

Para Milner (2005), a avaliação se orienta por uma "domesticação generalizada" (p. 12, tradução nossa) ao saber e se compromete a demonstrar a igualdade dos homens em substância calculável. Quanto mais avaliável e calculável, mais homem. É necessário consentir com sua objetificação. É necessário ser transparente, a si mesmo e aos outros. É o progresso do reino do "todos iguais", da "era do homem sem qualidades" (Miller, 2006, p. 1).

Milner (2005) realiza uma leitura da avaliação como a "palavra de ordem" (p. 10, tradução nossa) da atualidade. A ideologia dessa prática é efeito da reificação e da racionalidade, orientadas pelo capitalismo e pela ciência moderna. A avaliação, técnica que se pretende científica, é um instrumento da democracia moderna que invade a vida dos homens. Há a tentativa de tornar os indivíduos "coisas avaliáveis" (Milner, 2005, p. 17, tradução nossa) e, ao mesmo tempo, há a promessa de que os objetos, as coisas, vão governar.

Tratando o homem como um objeto mensurável para, assim, estabelecer uma igualdade demonstrável, a administração esconde que "os seres falantes são incomensuráveis e insubstituíveis" (Milner, 2005, p. 26, tradução nossa). Milner (2005) salienta que, na Revolução Francesa, a questão da incomensurabilidade dos homens foi tratada pela ideia de liberdade, que mantinha uma igualdade formal entre os homens. Essa igualdade formal significa que os homens eram "livres e iguais em direitos" (Milner, 2005, tradução nossa) e "a palavra 'direito' é necessária e suficiente para impedir que "livres e iguais' não sejam contraditórios" (Milner, 2005, p. 26, tradução nossa). Entretanto, no lugar da antiga igualdade formal, a democracia contemporânea, chamada pelo autor de "democracia verbal”, persegue a "igualdade substancial” (Milner, 2005, p. 26, tradução nossa).

$\mathrm{Na}$ Contemporaneidade, a ideia de homem passa a ser estabelecida pelo ideal da "boa igualdade, a moderna, aquela que abole passivamente as liberdades" (Milner, 2005, pp. 29-30, tradução nossa). Isso posto, a dignidade de um homem é definida pela avaliação, pois "o homem avaliado é mais homem que os outros porque ele é mais assimilável pelas coisas" (Milner, 2005, p. 29, tradução nossa). Nessa perspectiva, a avaliação toma o homem como objeto que pode ser calculado e medido por inteiro, física e psiquicamente. A avaliação se propõe a 
obter um saber demonstrável, "um saber transparente e comunicável ao Outro" (Miller, 2006, p. 13). Logo, é apresentada a tentativa de estabelecer uma relação de confiança entre os indivíduos e os coletivos, fundada no saber transparente da prática avaliativa. Por conseguinte, podemos relacionar essa forma de laço social que provém de um saber, calculável e verificável, ao utilitarismo e ao discurso universitário, pois o saber comanda e ocupa o lugar do agente.

A tentativa de subjetivar um coletivo pelo uso do saber é "um sonho burocrático" (Miller, 2006, p. 14). O modelo da administração burocrática é evocado por Lacan (1969-1970/1992) ao se referir ao discurso universitário e seu imperativo de "tudo saber". A passagem do discurso do mestre antigo para o discurso do mestre moderno, universitário e capitalista, é evidente nessa nova forma de laço social que tenta se garantir pelo manejo do saber demonstrável, em contraposição às prescrições da exceção, nunca demonstráveis ou calculáveis.

Miller e Milner (2006) ressaltam que a democracia contemporânea, ao supor uma equivalência entre os sujeitos, relaciona-se com o ideal de transparência e coloca tudo e todos sob vigilância e fiscalização contínuas. Laurent (2012a) expõe que, atualmente, verifica-se "a instalação de uma sociedade de vigilância com seu pan-óptico louco" (p. 37). Para elucidar essa questão, recordamos a indissociabilidade entre a vigilância e a máxima utilitária presentes no pan-óptico de Bentham. O pan-óptico pode ser relacionado a um complemento da lógica contratual, pois sua vigilância não exclui nenhum indivíduo, não existe um que esteja em posição de exceção. $\mathrm{Na}$ mesma lógica da vigilância pan-óptica, a avaliação não deixa espaço para a exceção, não existe um que não seja submetido a ela.

Assim como o utilitarismo propõe que todo indivíduo deve ser registrado, Miller e Milner (2006) sustentam que o importante da avaliação é que um ser seja avaliado, que a avaliação designe um saber sobre ele, que ele seja "mensurado, marcado, carimbado" (p. 21). Nas aproximações entre a avaliação, a vigilância e a lógica contratual é evidente que o imperativo de transparência se impóe a todos os sujeitos no mundo contemporâneo.

Wajcman (2011) trata das questôes da vigilância na atualidade e indica que o olhar onipresente da vigilância se propõe a ver tudo e ordena que "não devemos deixar nenhum ângulo morto na sociedade" (Wajcman, 2011, p. 97, tradução nossa). A vigilância é um instrumento que "consiste em captar imagens, transmiti-las, e logo analisá-las a fim de definir uma resposta" (Wajcman, 2011, p. 150, tradução nossa). Dessa forma, a ideia é transformar a imagem em uma mensagem que possa ser lida, em uma informação, em um saber. A vigilância é tomada como uma "máquina de tratar informação" (Wajcman, 2011, p. 150, 
tradução nossa) e como um sistema que indica qual decisão tomar, partindo de uma "noção cognitivista que supõe que tomar uma decisão é algo possível de ser modelizado - partindo de dados digitalizados em um algoritmo, em uma fórmula matemática, ou seja, universal” (Wajcman, 2011, p. 150, tradução nossa).

Desse modo, verificamos como o "tudo saber", imperativo da administração contratual e utilitária, inclui a vigilância como uma de suas estratégias. Como a avaliação, a vigilância incide sobre os indivíduos na busca de extrair um saber que possa ser visto e decodificado. A decifração do saber ocorre pela estatística e se estende aos diversos domínios da vida social.

Nesse sentido, Milner (2005) destaca que, na sociedade moderna, no reino da avaliação, ocorre o "desaparecimento dos mestres" (p. 59, tradução nossa). É ressaltado que, "em nome do controle, cada um se torna servo do outro" (Milner, 2005, p. 59, tradução nossa) e que, "no mundo da expertise e da avaliação, não há nada além de domesticados, de servos" (p. 59). Assim, ocorre a modificação das formas de identificação dos sujeitos. Se antes, no reino da lei, a identificação era propiciada pelo $S_{1}$, por um líder, uma exceção, no reino da norma a identificação, é oferecida por um $S_{2}$, por um saber extraído da avaliação. Segundo Miller (2006), o modelo de formação de um coletivo pela identificação, isolado por Freud (1921/2011) em Psicologia das massas e análise do eu, não é o mesmo do modelo contemporâneo. No discurso da avaliação, realiza-se a inédita tentativa de "dar ao coletivo sua unidade, através do saber, $S_{2}$ " (Miller, 2006, p. 14). Na identificação proposta pela avaliação, a função do líder, da exceção, não existe. Tenta-se "obter a subjetivação do coletivo unicamente por meio de saber, e de um saber homogêneo. A função do mais um, ou do menos um, é estritamente impensável nesse caso" (Miller, 2006, p. 14).

Nesse sentido, Laurent e Miller (2013) propõem que o matema da identificação proposto por Lacan, I(A), é substituído por I(A/). O que está em jogo nessa mudança na forma de identificação é que, anteriormente, o sujeito poderia extrair um $S_{1}$ do campo do Outro consistente (A) na forma de uma metáfora, como exposto no discurso do mestre. $\mathrm{Na}$ atualidade, com a inconsistência do Outro (A/), ocorrem “identificações débeis” (Laurent, \& Miller, 2013, p. 60, tradução nossa) e inconsistentes.

As múltiplas identificações possíveis são determinadas, na Contemporaneidade, pelo saber estabelecido por um coletivo de "especialistas que definirão o bem comum" (Miller, 2001, p. 59, tradução nossa). No mundo moderno, as exceções são inclusas e passam a serem prescritas pelo discurso normativo. Como bem salientam Laurent e Miller (2013), a "tentativa de fazer uma língua comum 
do discurso universitário qualificado de politicamente correto mascara a grande heterogeneidade da comunidade" (p. 60, tradução nossa). Nesse sentido, é importante retomar o que Laurent (2012b) indica:

Por um lado, as normas nem sempre conseguem fazer com que os corpos, por sua inscrição forçada, se insiram em usos padronizados, nessa máquina infernal na qual o significantemestre instala suas disciplinas de fazer marcas identificatórias (marquage) e de educação. Os corpos são muito mais deixados por sua própria conta, marcando-se febrilmente com signos que não chegam a lhes dar consistência. Por outro lado, a agitação do real pode ser lida como uma das consequências da "ascensão ao zênite" do objeto $a$. A apresentação da exigência de gozo em primeiro plano submete os corpos a uma 'lei de ferro' cujas consequências é preciso acompanhar (p. 1).

A proposta de tratamento do gozo oferecida pelo discurso do mestre moderno opera pelo seu ciframento em um saber calculável e padronizado, e também pelo seu oferecimento via gadgets, de forma homogeneizada, na promessa de tamponar o mal-estar e a divisão subjetiva. Promessa esta que parece não obter sucesso, como Lacan pontua, ao se perguntar se seremos animados pelos gadgets. Nesse sentido, ele destaca que isso "parece pouco provável. Não conseguiremos realmente fazer com que o gadget não seja um sintoma, pois ele o é, por enquanto, com toda a evidência" (Lacan, 1974, p. 19, grifo do autor).

Lacan (1974) aponta que o futuro da psicanálise é dependente do que advirá desse real da civilização contemporânea, ou seja, dos efeitos dessa ordem de ferro sobre os sujeitos. Mesmo apesar dos esforços do discurso do mestre moderno, há algo que resiste em ser apreendido pelo saber ou satisfeito pelos gadgets, e que resta na relação do sujeito com o laço social. Assim, Laurent (2016) sustenta que "é impossível a satisfação final, a reconciliação entre o sujeito e o gozo. O sujeito continua dividido por isso que ele não domina" (p. 107, tradução nossa).

A psicanálise se oferece para escutar esses efeitos e, de forma diferente do discurso do mestre moderno, dá lugar ao que do sintoma é opaco, ao que do gozo não se pode contabilizar ou significantizar. $\mathrm{Na}$ contramão do discurso utilitário e de seu ideal de transparência, a psicanálise se orienta pelo saber que não está explicitado e que não é calculável, mas que é inconsciente e surge sob transferência. O saber do inconsciente não é transparente e a relação analítica é impossível de ser contratualizada.

Não há uma direção da cura, entendida como erradicação do sintoma, como o discurso do mestre moderno pode sugerir. Considerando o que não pode se tornar transparente à linguagem e não pode ser erradicado da experiência humana, a psicanálise oferece outro destino para o íntimo, visando à construção de um estilo mediante o que é mais íntimo e êxtimo, do opaco do sinthoma. 


\section{REFERÊNCIAS}

Bentham, J. (1776/1988). A fragment on government. London: Cambridge University Press, 1988. (Publicado originalmente em 1776).

Bentham, J. (1787/2008). O pan-óptico. In T. T. Silva (Org.), O panóptico. (pp. 15-87). Belo Horizonte: Autêntica, 2008. (Publicado originalmente em 1787)

Bobbio, N. (1995). O positivismo jurídico: liçôes de Filosofia do Direito. M. Pugliesi, E. Bini, \& C. E. Rodrigues (Trads.). São Paulo: Ícone.

Brousse, M. H. (1999). Los quatro discursos y el Otro de la modernidad. Santiago de Cali: Letra.

Brousse, M. H. (2015, 6 abril). "La paz es un sueño; la guerra, una pesadilla”. Entrevista concedida a Pablo E. Chacón. Telam. Recuperado a partir de http:// www.telam.com.ar/notas/201504/100494-la-paz-es-un-sueno-la-guerra-unapesadilla.html

Foucault, M. (2015). Microfísica do poder. (2a ed.). R. Machado (Rev. Téc.). Rio de Janeiro: Paz e Terra.

Freud, S. (1921/2011). Psicologia das massas e análise do eu. In S. Freud. Psicologia das massas e análise do eu e outros textos (1920-1923). (pp. 13-113). São Paulo: Companhia das Letras, 2011. (Publicado originalmente em 1921).

Lacan, J. (1959-1960/2008). O Seminário, livro 7: a ética da psicanálise. Rio de Janeiro: Jorge Zahar. (Publicado originalmente em 1959-1960)

Lacan, J. (1960/1998). Subversão do sujeito e dialética do desejo. In J. Lacan. Escritos. (pp. 807-845). Rio de Janeiro: Jorge Zahar. (Publicado originalmente em 1960).

Lacan, J. (1967a/2003). Alocução sobre as psicoses das crianças. In J. Lacan. Outros escritos. (pp. 359-368). Rio de Janeiro: Jorge Zahar. (Publicado originalmente em 1967).

Lacan, J. (1967b/2003). Proposição de 9 de outubro de 1967 sobre o psicanalista da Escola. In V. Ribeiro (Trad.), Outros escritos. (pp. 248-264). Rio de Janeiro: Jorge Zahar, 2003. (Publicado originalmente em 1967)

Lacan, J. (1968-1969/2006). Le Séminaire, Livre XVI: d'un Autre à l'autre. Paris: Seuil, 2006. (Publicado originalmente em 1968-1969). 
Lacan, J. (1968-1969/2008). O Seminário, livro 16: de um Outro ao outro. Rio de Janeiro: Jorge Zahar, 2008. (Publicado originalmente em 1968-1969)

Lacan, J. (1969-1970/1991). Le Séminaire, Livre XVII: L'Envers de la psychanalyse. Paris: Seuil, 1991. (Publicado originalmente em 1969-1970).

Lacan, J. (1969-1970/1992). O Seminário, livro 17: o avesso da psicanálise. Rio de Janeiro: Jorge Zahar, 1992. (Publicado originalmente em 1969-1970).

Lacan, J. (1970/2003). Radiofonia. In J. Lacan. Outros escritos. (pp. 400-447). Rio de Janeiro: Jorge Zahar. (Publicado originalmente em 1970).

Lacan, J. (1971/2009). O Seminário, livro 18: de um discurso que não fosse semblante. Rio de Janeiro: Jorge Zahar, 2009. (Publicado originalmente em 1971).

Lacan, J. (1971-1972/2011). Estou falando com as paredes: conversa na Capela de Sainte-Anne. Rio de Janeiro: Jorge Zahar, 2011. (Publicado originalmente em 1971-1972).

Lacan, J. (1972). Du discours psychanalytique: conférence à l'université de Milan, le 12 mai 1972. Espaces Lacan. Recuperado a partir de http://espace. freud.pagesperso-orange.fr/topos/psycha/psysem/italie.htm

Lacan, J. (1973/2003). Nota italiana. In J. Lacan. Outros Escritos. (pp. 311-315). Rio de Janeiro: Jorge Zahar, 2003. (Publicado originalmente em 1973).

Laia, S. (2009). Análise e interpretação de uma efusão coletiva: os discursos, a ação lacaniana a partir de maio de 68 e suas consequências. Almanaque online: revista eletrônica do IPSM-MG, 3(4), 01-17. Recuperado a partir de http:// almanaquepsicanalise.com.br/wp-content/uploads/2015/09/Sergio-laia.pdf

Lalande, A. (1926/1988). Vocabulaire technique et critique de la philosophie. (Vol. 2, 7 a ed.). Paris: PUF. (Publicado originalmente em 1926).

Laurent, É. (1992). Lacan y los discursos. (pp. 11-45). Buenos Aires: Manantial.

Laurent, É. (2012a). A ordem simbólica no século XXI. M. C. M. Fernandes (Trad.). In Papers no 1, 8, Congreso Asociación Mundial de Psicoanálisis. (pp. 33-41). Buenos Aires: AMP. Recuperado a partir de http://2012.congresoamp. com/Papers/Papers-001.pdf

Laurent, É. (2012b). Falar com seu sintoma, falar com seu corpo. In Anais, 6, Encontro Americano de Psicanálise da Orientação Lacaniana, 18, Encontro 
Internacional do Campo Freudiano. Recuperado a partir de http://www.enapol. $\mathrm{com} / \mathrm{pt} /$ template.php?file=Argumento/Hablar-con-el-propio-sintoma_EricLaurent.html

Laurent, É. (2016). Lectura irónica. In J.-A. Miller. Un esfuerzo de poesia. (pp. 103-109). Buenos Aires: Paidós.

Laurent, É., \& Miller, J.-A. (2013). El Otro que no existe y sus comités de Ética. Buenos Aires: Paidós.

Lizárraga, F. (2015). El vínculo igualitario en el contratualismo: la mirada rawlsiana sobre Rousseau. In M. A. Rossi (Org.), El lazo social desde la filosofia politica. (pp. 51-80). Buenos Aires: Grama.

Lukács, G. (2003). História e consciência de classe: estudos sobre a dialética marxista. São Paulo: Martins Fontes.

Mackenzie, I. (2011). Política: conceitos-chave em filosofia. Porto Alegre: Artmed.

Miller, J.-A. (2001). De la naturaleza de los semblantes. Buenos Aires: Paidós.

Miller, J.-A. (2005a). O sobrinho de Lacan. Rio de Janeiro: Forense Universitária.

Miller, J.-A. (2005b). Uma fantasia. Opção Lacaniana, 42, 7-18.

Miller, J.-A. (2006). A era do homem sem qualidades. Asephallus, 1(1), 1-16. Recuperado a partir de http://www.isepol.com/asephallus/numero_01/ traducao.htm

Miller, J.-A. (2008). A máquina panóptica de Jeremy Bentham. In T. T. Silva (Org.), O panóptico. (pp. 89-124). Belo Horizonte: Autêntica.

Miller, J.-A., \& Milner, J.-C. (2006). Você quer mesmo ser avaliado?: entrevistas sobre uma máquina de impostura. Barueri: Manole.

Milner, J.-C. (2002). Les pouvoirs: d'un modèle à l'autre. Révue Élucidation, 6/7.

Milner, J.-C. (2005). La politique des choses. Paris: Navarin.

Oliveira, M. S. S. (2017). Efeitos do apagamento da exceção na Contemporaneidade. (Dissertação de Mestrado). Programa de Pós-Graduação em Psicologia, Universidade Federal de Minas Gerais, Belo Horizonte.

Rousseau, J.-J. (1762/2014). O contrato social. Porto Alegre: L\&PM, 2014. 
(Publicado originalmente em 1762).

Sartre, J.-P. (1994). O que é um intelectual? In J.-P. Sartre. Em defesa dos intelectuais. (pp. 13-31). São Paulo: Ática.

Teixeira, A. M. R. (1999). O topos ético da psicanálise. Porto Alegre: EdiPUCRS.

Teixeira, A. M. R. (2012). Ready for love: violência e exceção em Clockwork Orange. Artefilosofia, 12, 217-228. Recuperado a partir de http://www.raf.ifac. ufop.br/pdf/artefilosofia_12/(15)antonio\%20teixeira.pdf

Teixeira, A. M. R. (2015). A fundação violenta do Universal. Derivas Analíticas, 3, 1-5. Recuperado a partir de http://www.revistaderivasanaliticas.com.br/ index.php/accordion-a-3/universal

Wajcman, G. (2011). El ojo absoluto. Buenos Aires: Manantial. 